\title{
Are 25(OH)D Levels Related to the Severity of Knee Osteoarthritis and Function?
}

\author{
Khaled F. Al-Jarallah ${ }^{a}$ Diaa Shehab ${ }^{a}$ Adel Al-Awadhi ${ }^{a} \quad$ Ibrahim Nahar $^{d}$ \\ Mohammad Z. Haider ${ }^{b}$ Mohamed A. Moussac \\ Departments of a Medicine, ${ }^{b}$ Pediatrics and ${ }^{c}$ Community Medicine, Faculty of Medicine, Kuwait University, and \\ ${ }^{\mathrm{d}}$ Department of Medicine, Ministry of Health, Jabriya, Kuwait
}

\section{Key Words}

Vitamin D $\cdot$ Knee osteoarthritis $\cdot$ Functional status $\cdot$ Kuwait

\begin{abstract}
Objective: To investigate the effect of 25-hydroxyvitamin D $[25(\mathrm{OH}) \mathrm{D}]$ in Kuwaiti patients with primary knee osteoarthritis $(\mathrm{OA})$ and to assess its relation with radiological grading and functional status. Subjects and Methods: In this crosssectional study, 25(OH)D was measured using radioimmunoassay in 99 patients [ 90 women and 9 men; mean age 56.5 \pm 9.1 years (range: $36-80$ )] with clinical and radiological findings of primary knee OA. X-ray grading using the Kellgren-Lawrence grading scale and the Osteoarthritis Research Society International (OARSI) Atlas grading scale and functional assessments using Lequesne's indices were evaluated in relation to the $25(\mathrm{OH}) \mathrm{D}$ level. Other variables studied were age at onset of symptoms, body mass index and duration of disease. Results: The age of the patients at the onset and the duration of disease were $51.58 \pm 7.14$ and $3.88 \pm$ 2.51 years, respectively. Mean scoring for functional assessment was $10.31 \pm 4.35$ and mean Kellgren-Lawrence radiological grading was $2.43 \pm 0.85$. Radiological finding according to the OARSI Atlas revealed joint space narrowing of grades 2-3 in 87 (87.9\%) patients and the presence of osteo-
\end{abstract}

(c) 2011 S. Karger AG, Basel

$1011-7571 / 12 / 0211-0074 \$ 38.00 / 0$

Fax +4161306 1234

E-Mail karger@karger.ch

www.karger.com
Accessible online at: www.karger.com/mpp phytes in $55(55.6 \%)$ patients. The mean value of $25(\mathrm{OH}) \mathrm{D}$ level was $11.4 \pm 6.07 \mathrm{ng} / \mathrm{ml}$. Of the 99 patients, 92 (92.9\%) were vitamin D deficient. Comparison of 25(OH)D levels to radiological findings and different functional classes showed no significant association. Conclusion: Most of our patients had vitamin D deficiency, but the level of $25(\mathrm{OH}) \mathrm{D}$ was not related to the severity of the knee X-ray grading or to the functional assessment in our patients with primary knee OA.

Copyright $\odot 2011$ S. Karger AG, Basel

\section{Introduction}

Osteoarthritis (OA) is characterized by loss of cartilage and concomitant changes in subchondral bone; it is the most common cause of musculoskeletal disability in the elderly. Normal bone and cartilage metabolism depends on the presence of vitamin D [1]. Insufficient levels of vitamin $\mathrm{D}$ have been shown to have adverse effects on calcium metabolism, osteoblastic activity, matrix ossification, bone density and articular cartilage turnover [25]. Observational epidemiological studies have suggested that vitamin D status may affect the occurrence and progression of OA [1, 6-11]. Vitamin D is active in the bone and the remodeling of the bone which may be critical for

Dr. K.F. Al-Jarallah

Medicine Department, Faculty of Medicine, Kuwait University PO Box 24923

Safat 13110 (Kuwait)

Tel. +965 2531 9596, E-Mail aljarallah@ @sc.edu.kw 
disease stability in OA [6]. While growth plate cartilage is responsive to vitamin $\mathrm{D}$, hypertrophic adult articular chondrocytes redevelop receptors for vitamin $\mathrm{D}$ which may influence these chondrocytes and alter somehow their metabolic process [7].

Knee OA is common in Kuwait $[12,13]$ yet no specific factors have been studied so far. Two genetic studies did not reveal any association with knee OA $[14,15]$. Vitamin $\mathrm{D}$ supplements may be prescribed to patients with knee OA to 'improve knee OA'. Therefore, the objective of this study was to investigate the effect of serum levels of 25hydroxyvitamin D [25(OH)D] in Kuwaiti Arab patients with primary knee $\mathrm{OA}$ and to assess its associations with the radiological grading and functional status of the patients.

\section{Subjects and Methods}

\section{Study Populations}

This is a cross-sectional study which included 99 consecutive patients (90 women and 9 men) with primary knee OA who were recruited over 1 year from 2 rheumatology clinics (Mubarak AlKabir and Al-Amiri hospitals). All the patients had clinical and radiological evidence of knee OA with no underlying inflammatory diseases. All the patients were evaluated clinically, radiologically as well as for functional assessment. Other variables included were age at the onset of symptoms, body mass index (BMI) and duration of the symptoms. The study was approved by the Medical Research Ethics Committee, Faculty of Medicine, Kuwait University, Kuwait.

\section{Clinical Evaluation}

A detailed history and physical examination regarding knee pain was done. This included location, duration, severity of pain using the Visual Analogue Scale and patient global assessment of pain, the presence of swelling, nocturnal pain, pain at rest or activity (stairs, kneeling and squatting), stiffness/gelling phenomena as well as the clinical signs of OA such as bone broadening, knee crepitus, tenderness and range of motions.

\section{Radiographic Assessment}

$\mathrm{X}$-rays of the knee were taken at an anteroposterior position and weight bearing was assessed using the Kellgren-Lawrence grade on a Likert scale from 0 to 4 . Grades 1-2 were considered as mild and grades 3-4 as severe. All the patients were also scored for joint space narrowing (JSN) and osteophytes separately on a scale from 0 to 3 ( 0 = normal; $3=$ severe $)$ according to the Osteoarthritis Research Society International (OARSI) Atlas [11].

\section{Functional Assessment}

All patients were assessed for function using Lequesne's indices; a value of less than 10 was considered a good index while a value of 10 or more was considered to be a poor index. Assessment mainly included activities of daily living such as walking, climbing stairs, squatting and kneeling.

Vitamin D Deficiency and Knee Osteoarthritis
Measurement of Vitamin D Level: Plasma 25(OH)D

Assessment

Blood samples were collected and were anti-coagulated with EDTA and the plasma was separated by centrifugation at 2,500 $\mathrm{rpm}$. The plasma was then used in the vitamin D assays. Plasma was stored at $-70^{\circ} \mathrm{C}$ until used for analysis. Plasma 25(OH)D concentration was determined by radioimmunoassay kits (DiaSorin, Stillwater, Minn., USA). The analysis consisted of two procedures: the first involved rapid extraction of $25(\mathrm{OH}) \mathrm{D}$ and other hydroxylated metabolites from the plasma which were treated with acetonitrile, and were then assayed using an equilibrium RIA procedure. The intra- and interassay coefficients of variation were obtained and were 5.4 and $7.8 \%$, respectively. The vitamin D level was defined as deficient when $25(\mathrm{OH}) \mathrm{D}$ was $<20 \mathrm{ng} / \mathrm{ml}[16-18]$. Calcium, parathyroid hormone and serum albumin were also measured.

\section{Statistical Analysis}

The Statistical Package for Social Sciences (SPSS) version 17 was used for data processing (Chicago, Ill., USA). Comparison of different variables among the two levels (deficient $<20 \mathrm{ng} / \mathrm{ml}$ and normal $\geq 20 \mathrm{ng} / \mathrm{ml}$ ) of $25(\mathrm{OH}) \mathrm{D}$ was done using the independentsamples $t$ test. When data were skewed, the Mann-Whitney U test was used. The association between JSN and osteophytes was conducted using Pearson's $\chi^{2}$ test. Univariate and multivariate logistic regression was used to examine the association between OA and $25(\mathrm{OH}) \mathrm{D}$ levels which were adjusted for age, gender and BMI. The variables used were JSN and osteophytes, in accordance with the OARSI Atlas grading scale.

\section{Results}

The mean age was $56.49 \pm 9.12$ years (range: $36-80$ ). The characteristics of the 99 patients including age of disease onset, duration of disease in years, BMI, functional and radiological grading are given in table 1 . Serum calcium, parathyroid hormone and albumin levels were within normal limits. The mean value of $25(\mathrm{OH}) \mathrm{D}$ level was $11.4 \pm 6.07 \mathrm{ng} / \mathrm{ml}$ and $92(92.9 \%)$ patients were vitamin $\mathrm{D}$ deficient. Radiological finding based on the OARSI Atlas grading scale revealed JSN in all the patients but JSN of grade $2-3$ was seen in $87(87.9 \%)$ patients (fig. 1) and the presence of osteophytes was observed in $55(55.6 \%)$ patients in the medial and lateral tibiofemoral compartments at right and left knees combined. The comparison of the variables including age, BMI, duration of knee OA, function and X-ray grading to the two levels of $25(\mathrm{OH}) \mathrm{D}$ (deficient $<20 \mathrm{ng} / \mathrm{ml}$ and normal $\geq 20 \mathrm{ng} /$ $\mathrm{ml}$ ) revealed no significant difference between the levels of these variables and those of vitamin D. Eighty-two (88.2\%) patients with $25(\mathrm{OH}) \mathrm{D}$ deficiency also showed JSN and $53(57.0 \%)$ patients with 25(OH)D deficiency also exhibited osteophytes (table 2). The association between 
Table 1. Characteristics of patients with knee OA $(n=99)$

\begin{tabular}{lc}
\hline Characteristics & \\
\hline Age, years & $56.49 \pm 9.12$ \\
Gender, male/female & $9 / 90$ \\
BMI, kg/m ${ }^{2}$ & $31.43 \pm 6.26$ \\
Age of onset, years & $51.58 \pm 7.14$ \\
Duration of OA, years & $3.88 \pm 2.51$ \\
Calcium, mmol/l & $2.28 \pm 0.13$ \\
PTH, ng/l & $20.5 \pm 17.04$ \\
Albumin, g/l & $37.64 \pm 4.6$ \\
Vitamin D, ng/ml & $11.4 \pm 6.07$ \\
Kellgren-Lawrence grade & $14(14.14)$ \\
$\quad 1$ & $41(41.41)$ \\
2 & $35(35.35)$ \\
3 & $9(9.09)$ \\
$\quad 4$ & \\
X-ray grading according to OARIS & $12(12.1)$ \\
$\quad$ JSN & $87(87.9)$ \\
$\quad$ Grade 1 & $44(44.4)$ \\
Osteophytes & $55(55.6)$ \\
$\quad$ Grade 0 & $10.40 \pm 4.47$ \\
Function (Lequesne's indices) & \\
\hline
\end{tabular}

$\mathrm{PTH}=$ Parathyroid hormone. Figures are means $\pm \mathrm{SD}$ or number of patients with percentages in parentheses.

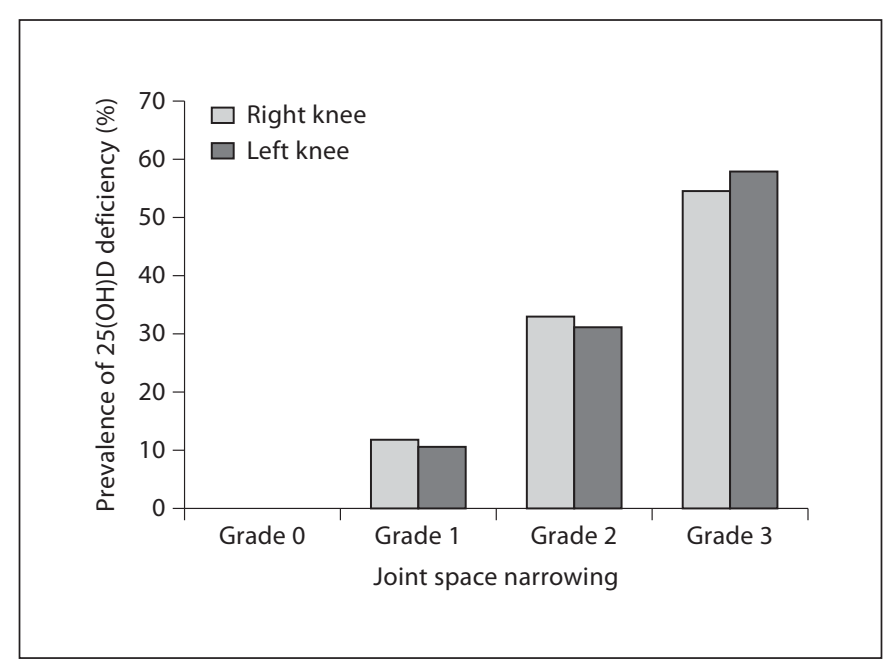

Fig. 1. Vitamin D deficiency and JSN scored on a scale from 0 to 3 .
$25(\mathrm{OH}) \mathrm{D}$ and $\mathrm{OA}$ adjusted for age, gender and BMI using the logistic regression analysis is given in table 3. Crosssectionally, 25(OH)D levels were not associated with JSN or osteophytes in the medial tibiofemoral compartment at both right and left knees together in both univariate and multivariate analyses, after adjusting for the confounders age, gender and BMI.

\section{Discussion}

Our study showed that most of our patients with primary knee OA had 25(OH)D deficiency which could be due to cultural practice such as clothing. The majority of the women wear long garments and cover their heads although Kuwait is a very sunny place with sunshine almost all year round. Yet, the exposure of females to sun is low. Although the majority of patients with knee OA had $25(\mathrm{OH}) \mathrm{D}$ deficiency, we could neither associate it with the radiological severity of knee OA nor with the functional ability. Two longitudinal epidemiologic studies $[1,8]$ had shown that low vitamin D levels worsen the course of OA: the Framingham study cohort [8] which showed that subjects with preexisting knee OA and who have vitamin $\mathrm{D}$ levels in the lowest and middle tertiles had a 3-fold risk of radiographic worsening of the knee OA, while the other study [1] showed that levels of vitamin $\mathrm{D}$ in the lowest and middle tertiles were associated with hip OA.

Felson et al. [7] had reported the level of $25(\mathrm{OH}) \mathrm{D}$ from two longitudinal cohort studies, namely the Framingham osteoarthritis study [18] and the Boston osteoarthritis knee study showing that vitamin D status is unrelated to the risk of joint space or cartilage loss in knee OA or worsening of the knee OA. More recently, McAlindon et al. [19] showed that vitamin D supplement at a dose sufficient to increase the levels of vitamin $\mathrm{D}$ to above $30 \mathrm{ng} / \mathrm{ml}$ did not appear to have any benefit for pain or structural progression of knee OA. Although our study was not a longitudinal study, our data demonstrated that in the Arab patients with knee OA with different radiological grading (Kellgren-Lawrence grade mild vs. severe as well as OARSI Atlas grading scale), there was no association with $25(\mathrm{OH}) \mathrm{D}$ levels. The majority of patients with 25(OH)D deficiency showed JSN of grades 2 and 3 (88.2\%) in the medial tibiofemoral compartment, right and left combined (fig. 1). A lesser proportion of patients (57.0\%) with $25(\mathrm{OH}) \mathrm{D}$ deficiency presented with grade 1 osteophyte formation. These findings are consistent with those of Ding et al. [11]. However, and most probably be- 
Table 2. Binary logistic regression analysis showing the association between $25(\mathrm{OH}) \mathrm{D}$ and knee radiographic $\mathrm{OA}$ (in the medial tibiofemoral compartments at the right and left knees combined)

\begin{tabular}{lll}
\hline & Univariate OR $(95 \% \mathrm{CI})$ & ${\text { Multivariate OR }(95 \% \text { CI })^{\mathrm{a}}}$ \\
\hline JSN & & \\
$\quad$ Grade 1 (reference) & 1.000 & 1.000 \\
$\quad$ Grades 2 and 3 & $1.491(0.159-13.968)$ & $2.683(0.228-31.632)$ \\
Osteophytes & 1.000 & 1.000 \\
$\quad$ Grade 0 (reference) & $2.650(0.462-15.194)$ & $1.283(0.165-9.953)$ \\
$\quad$ Grade 1 &
\end{tabular}

The dependent variable is JSN or osteophytes in the medial tibiofemoral compartments. The independent variable is $25(\mathrm{OH}) \mathrm{D}$ level $<20 \mathrm{vs} . \geq 20 \mathrm{ng} / \mathrm{ml}$. ${ }^{\text {a }}$ Adjusted for age, gender and BMI.

Table 3. Relationship between vitamin D and variables of interest

\begin{tabular}{lccc}
\hline & \multicolumn{2}{c}{ Vitamin D levels } & p value \\
\cline { 2 - 3 } & $\begin{array}{l}\text { deficient }^{\mathrm{a}} \\
(\mathrm{n}=93)\end{array}$ & $\begin{array}{l}\text { normal }^{\mathrm{a}} \\
(\mathrm{n}=6)\end{array}$ & \\
\hline Age, years & $56.7 \pm 9.5$ & $57.1 \pm 3.3$ & $0.909^{\mathrm{b}}$ \\
BMI, kg/m & $31.7 \pm 6.5$ & $29.4 \pm 3.5$ & $0.507^{\mathrm{c}}$ \\
Duration of OA, years & $5.5 \pm 4.6$ & $7.0 \pm 5.1$ & $0.707^{\mathrm{c}}$ \\
Function & $10.5 \pm 4.4$ & $8.4 \pm 2.9$ & $0.294^{\mathrm{b}}$ \\
X-ray grading & $2.3 \pm 0.82$ & $2.3 \pm 1.0$ & $0.894^{\mathrm{b}}$ \\
X-ray grading by OARIS Atlas & & \\
$\quad$ JSN & $11(11.8)$ & $1(16.7)$ & $0.549^{\mathrm{d}}$ \\
$\quad$ Grade 1 & $82(88.2)$ & $5(83.3)$ & \\
$\quad$ Grades 2 and 3 & & & \multirow{2}{*}{ Osteophytes } \\
$\quad$ Grade 0 & $40(43.0)$ & $4(66.7)$ & $0.940^{\mathrm{d}}$ \\
$\quad$ Grade 1 & $53(57.0)$ & $2(33.3)$ & \\
\hline
\end{tabular}

Figures are means $\pm \mathrm{SD}$ or number of patients with percentages in parentheses.

${ }^{\mathrm{a}}$ Deficient $<20 \mathrm{ng} / \mathrm{ml}$; normal $\geq 20 \mathrm{ng} / \mathrm{ml}$. ${ }^{\mathrm{b}}$ Independent-samples t test. ${ }^{\mathrm{c}}$ Mann-Whitney $U$ test. ${ }^{\mathrm{d}}$ Pearson's $\chi^{2}$ test.

cause of the small number of patients with normal $25(\mathrm{OH})$ $\mathrm{D}$ in our study group, both JSN and osteophytes did not show a significant association with $25(\mathrm{OH}) \mathrm{D}$ levels using univariate and multivariate analyses. Also, when the levels were studied in relation to the functional status of the patients (good vs. poor), which has not been reported before, we found no association of the functional index with the vitamin D status. Vitamin D deficiency may affect other aspects of knee OA such as pain or muscle weakness
[7], but does not affect the progression of knee OA [19]. Patients should be advised to reduce their weight and perform quadriceps knee exercises to improve their symptoms.

Our study has some limitations: first, it was not a longitudinal study, we included and followed patients who were referred to the rheumatologists for knee pain and who were diagnosed with primary knee OA. Second, the number of the subjects was relatively small, principally because the total population of the country is small and equally important Kuwaitis constitute approximately $40 \%$ of a total population of about 3 million. We would like to point out that the power analysis done on our sample size of 99 yielded $75.1 \%$, but to draw proper inference the power should have been at least $80 \%$. Despite these limitations, we are of the opinion that our findings suggest that there is no good association between vitamin $\mathrm{D}$ deficiency and severity of knee OA, especially considering the recent publication of the randomized study in Caucasian patients with knee OA [19].

Most of our patients had vitamin deficiency but the level of $25(\mathrm{OH}) \mathrm{D}$ was not related to the severity of the knee X-ray grading or to the functional assessment in our patients with primary knee OA.

\section{Acknowledgements}

The technical assistance of Mrs. Jalaja Sukumaran and Dr. Mini Abraham is gratefully appreciated. 


\section{References}

$>1$ Lane NE, Gore LR, Cummings SR, Hochberg MC, Scott JC, William EN, Nevitt MC: Serum vitamin $\mathrm{D}$ levels and incident changes of radiographic hip osteoarthritis. Arthritis Rheum 1999;42:854-860.

$\checkmark 2$ Shwartz Z, Bonewald L, Caulfield F, Brooks B, Boyan BD: Direct effects of transforming growth factors-B on chondrocytes are modulated by vitamin metabolites in a cell maturation specific manner. Endocrinology 1993; 132:1544-1552.

3 Parfitt AM, Gallagher JC, Heany RP, Johnston CC, Neer R, Whedon G: Vitamin D and bone health in the elderly. Am J Clin Nutr 1982;35:1014-1031.

4 Corvol MT, Dumontier MF, Tsagris L, Lang F, Bourguignon J: Cartilage and vitamin D in vitro. Ann Endocrinol 1981;42:482-487.

$\checkmark 5$ Dean DD, Boyan BD, Muniz OE, Howell DS, Shwartz Z: Vitamin D metabolites regulates matrix vesicle metalloproteinease content in a cell maturation-dependent manner. Calcif Tissue Int 1996;59:109-116.

6 Dieppe P, Cushnaghan J, Young P, Kirwan J: Prediction of the progression of joint space narrowing in osteoarthritis of the knee by bone scintigraphy. Ann Rheumat Dis 1993; 52:557-563.

$>7$ Felson D, Niu J, Clancy M, Aliabadi P, Sack B, Guermazi A, Hunter D, Amin S, Rogers G, Booth SL: Low levels of vitamin D and worsening of knee osteoarthritis. Arthritis Rheum 2007;56:129-136.
$>8$ McAlindon T, Felson D, Zhang Y, Hannan M, Aliabadi P, Weissman B, Rush D, Wilson PWF, Jacques P: Relation of dietary intake and serum levels of vitamin $\mathrm{D}$ to progression of osteoarthritis of the knee among participants in the Framingham Study. Ann Int Med 1996;125:353-359.

$>9$ Bergink AP, Uittertinden AG, Van Leeuween JP, Buurman CJ, Hofman A, Verhaar JA, Pols HA: Vitamin D status, bone mineral density, and the development of radiographic osteoarthritis of the knee: the Rotterdam Study. J Clin Rheumatol 2009;15:230-237.

10 Chaganti RK, Parimi N, Cawthon P, Dam TL, Nevitt MC, Lane NE: Association of 25-hydroxyvitamin D with prevalent osteoarthritis of the hip in elderly men. Arthritis Rheum 2010;62:511-514.

11 Ding C, Cicuttini F, Parameswaran V, Burgess J, Quinn S, Jones G: Serum levels of vitamin D, sunlight exposure, and knee cartilage loss in older adults. Arthritis Rheum 2009;60:1381-1389.

12 Al-Awadi A, Olusi S, Moussa M, Shehab D, Al Zaid N, Al-Herlz A, Al-Jarallah K: Musculoskeletal pain, disability and health-seeking behavior in adult Kuwaitis using a validated Arabic Version of the WHO-ILAR COPCORD Core Questionnaire. Clin Exp Rheumatol 2004;22:177-183.

13 Malaviya AN, Shehab D, Bhargava S, Al-Jarallah K, Al-Awadhi A, Sharma PN, Al-Ghuriear S, Al-Shugayer A: Characteristics of osteoarthritis among Kuwaitis: a hospital-based study. Clin Rheumatol 1998;17:210-213.
14 Al-Jarallah K, Shehab D, Haider MZ: Prevalence of the Pro12Ala missense mutation in the PPARG 2 gene in Kuwaiti patients with primary osteoarthritis of the Knee. Ann Saudi Med 2011;31:35-39.

15 Shehab D, Al-Jarallah K, Al-Awadhi A, AlHerz A, Nahar I, Haider MZ: Prevalence of angiotensin-converting enzyme gene insertion-deletion polymorphism in patients with primary knee osteoarthritis. Clin Exp Rheumatol 2008;26:305-310.

16 Holick MF: High prevalence of vitamin D inadequacy and implications for health. Mayo Clin Proc 2006;81:353-373.

17 Bischoff-Ferrari HA, Giovannucci E, Willett WC, Dietrich T, Dawson-Hughes B: Estimation of optimal serum concentrations of 25-hydroxyvitamin D for multiple health outcomes. Am J Clin Nutr 2006;84:18-28.

18 Malabanan A, Veronikis IE, Holick MF: Redefining vitamin D insufficiency. Lancet 1998;351:805-806.

19 McAlindon TE, Dawson-Hughes B, Driban J, Lavalley M, Lee Ji, Lo GH, Nuite M, Price LL: Clinical trial of vitamin $\mathrm{D}$ to reduce pain and structural progression of knee osteoarthritis. American College of Rheumatology Meeting, Atlanta, November 2010 